\title{
Overactive bladder symptom severity, bother, help-seeking behavior, and quality of life in patients with type 2 diabetes: a path analysis
}

\author{
Dongjuan $\mathrm{Xu}^{1,2}$, Meng Zhao ${ }^{1}$, Liqun Huang ${ }^{1}$ and Kefang Wang ${ }^{1 *}$
}

\begin{abstract}
Background: This study aimed to investigate the relationships among overactive bladder (OAB) symptom severity, bother, help-seeking behavior, and quality of life (QOL) in patients with type 2 diabetes.

Methods: A total of 127 diabetic patients, aged at least 18 years, with overactive bladder from a hospital in Shandong Province, China, were recruited for this study. Symptom severity, bother, and quality of life were assessed using the Overactive Bladder Symptom Score (OABSS), Patient Perception of Bladder Condition (PPBC), and Overactive Bladder Questionnaire Short Form (OAB-q SF), respectively. Help-seeking behavior was assessed by asking patients whether they consulted health care professionals or received treatment for their bladder problems. A two-step path analysis was performed to analyze the data.
\end{abstract}

Results: $\mathrm{OAB}$ symptom severity was directly associated with lower levels of $\mathrm{QOL}$, and the strength of this association was no longer significant when taking bother and help-seeking behavior into account. Bother increased with $O A B$ symptom severity, and patients with bothersome OAB tended to have lower levels of QOL. Moreover, bother increased help-seeking behavior; however, patients who sought help tended to have lower levels of QOL.

Conclusions: Our findings highlight the role of bother and help-seeking behavior in the relationship between $O A B$ symptom severity and QOL. To improve a patient's QOL, health care providers should focus not only on symptom bother but also on dysfunctional help-seeking patterns.

Keywords: Overactive bladder, Symptom severity, Quality of life, Help-seeking behavior, Bother

\section{Background}

Overactive bladder $(\mathrm{OAB})$ syndrome is defined as "urinary urgency, usually accompanied by frequency and nocturia, with or without urgency urinary incontinence" [1]. Nearly $11 \%$ of the worldwide population (455 million) is affected by $\mathrm{OAB}$, and the burden is expected to be the greatest in Asia [2]. In China, OAB symptoms have been found to affect more than 1 in 5 adults aged $\geq 40$ years [3]. The total cost is estimated to be at $\$ 65.9$ billion in 2007 in the Unites States alone [4]. The

\footnotetext{
* Correspondence: wangkf@sdu.edu.cn

Dongjuan Xu and Meng Zhao contributed equally to this work.

${ }^{1}$ School of Nursing, Shandong University, No. 44, Wenhua Xi Road, Jinan,

Shandong 250012, People's Republic of China

Full list of author information is available at the end of the article
}

financial cost is substantial not only in Western countries [5], but also in Asian countries [6]. Moreover, previous literature consistently presented a negative association between $\mathrm{OAB}$ and $\mathrm{QOL}$, using either a generic or a disease-specific QOL measure [7, 8].

With respect to the factors influencing QOL in patients with $\mathrm{OAB}$, empirical studies have emphasized on $\mathrm{OAB}$ symptom severity as a key determinant $[9,10]$. Vaughan et al. found that increased OAB symptom severity was directly associated with QOL deterioration across all dimensions [9]. In addition, a positive association between $\mathrm{OAB}$ symptom severity and experience of symptom bother was noted [10,11]. It was not only urge incontinence that patients found debilitating; nocturia and urgency were also considered bothersome $[12,13]$. 
However, symptom severity did not engender bother straightforwardly $[14,15]$. Some individuals were severely bothered by a small amount of leakage, whereas others were only slightly bothered by heavy leakage [15]. A previous study found that roughly one in three with urge incontinence and one in seven with urgency reported moderate or major bother [9]. Moreover, the experience of symptom of bother adversely affected many aspects of QOL, including daily life activities, work productivity, social interactions, and emotional wellbeing [16]. Therefore, investigating the relationships among $\mathrm{OAB}$ symptom severity, bother, and QOL is essential.

Although only a small proportion of affected individuals actually consulted physicians or received treatment for $\mathrm{OAB}[8,17]$, previous studies have indicated that perceived symptom severity and degree of bother are key reasons for help-seeking behavior [13, 14]. In addition to a direct relationship, symptom severity also had an indirect relationship with help-seeking behavior, i.e. via bother [18]. Bother appears to influence helpseeking behavior more than the symptoms themselves do [19]. Irwin et al. showed that about $52 \%$ of bothered individuals with $\mathrm{OAB}$ reported consulting their physicians, whereas $21 \%$ were not bothered [12]. Xu et al. also found that only women bothered by incontinence had intentions to seek help, regardless of symptom severity [15]. Individuals with OAB benefit from consulting their physicians and receiving treatments for their symptoms, especially as effective treatments are available. Behavioral interventions, such as pelvic floor muscle training, bladder training, and urge suppression techniques, can be used to extend voiding interval and reduce urgency and incontinence [20-22]. Moreover, behavioral interventions may increase the efficacy of pharmacotherapy [22], which consequently helps alleviate symptoms, prevent $\mathrm{OAB}$ recurrence, and improve QOL. However, previous studies have not considered $\mathrm{OAB}$ symptom severity, bother, help-seeking behavior, and QOL together. Thus, little is known about the role of bother and help-seeking behavior in the relationship between symptom severity and QOL.

This study was conducted using the existing data from $\mathrm{OAB}$ patients with type 2 diabetes. Diabetes contributes to an earlier onset and increases severity of bladder dysfunction [23], and $\mathrm{OAB}$ occurs more commonly in patients with type 2 diabetes than in the general adult population [24]. Thus, this study aimed to investigate the relationships among OAB symptom severity, bother, help-seeking behavior, and QOL in patients with type 2 diabetes in Mainland China, as illustrated in Fig. 1. Our hypotheses are as follows:

Hypothesis 1 . OAB symptom severity is associated with lower levels of QOL.

Hypothesis 2. Bother increases with OAB symptom severity, and patients with bothersome $\mathrm{OAB}$ are more likely to have lower levels of QOL.

Hypothesis 3 . Both OAB symptom severity and bother are expected to be associated with help-seeking behavior, and patients who sought help are more likely to have higher levels of QOL.

Hypothesis 4. The strength of the association between $\mathrm{OAB}$ symptom severity and QOL assumed in hypothesis 1 is attenuated when taking bother and help-seeking behavior into account.

\section{Methods}

\section{Study design and sample}

This is a cross-sectional design. This study included a subpopulation of a larger study measuring $\mathrm{OAB}$, toileting behaviors, and QOL among patients with type 2 diabetes [25]. The diabetic patients were recruited from May to August 2014 from the endocrinology outpatient department of a non-profit teaching hospital, which is one of the two largest hospitals in Shandong Province,

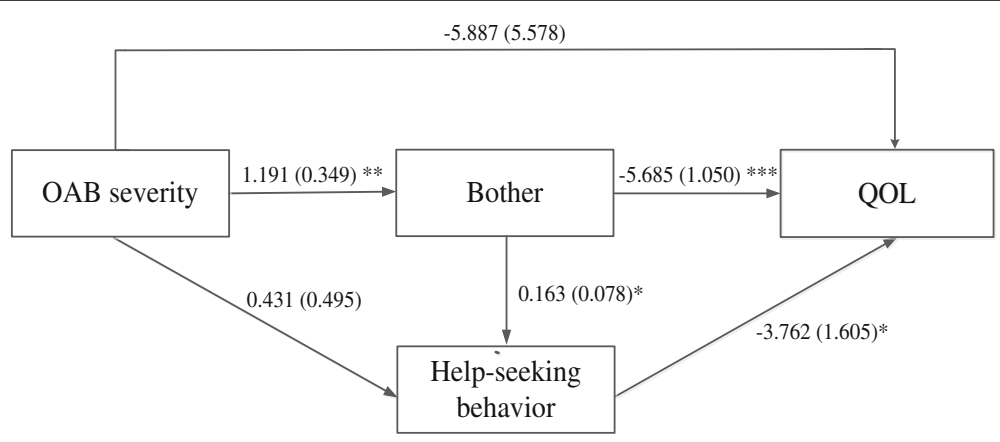

Fig. 1 Path diagram of the relationships among OAB severity, bother, help-seeking behavior, and QOL. Path coefficients with standard errors in parentheses are shown along the path arrows. The path analysis was adjusted for age, sex, years of education, marital status, living area, income, body mass index, urinary tract infection history, Charlson Comorbidity Index, duration of diabetes, and diabetes treatment (insulin or anti-diabetic medication) ${ }^{*} p<0.05,{ }^{* *} p<0.01,{ }^{* * *} p<0.001$. 
China. The larger study had 1025 eligible diabetic patients, of which 142 patients had OAB. Fifteen patients with $\mathrm{OAB}$ had missing data and thus were excluded from the analyses. Consequently, a total of 127 diabetic patients with $\mathrm{OAB}$ were included in this study. The inclusion criteria were as follows: (1) $\geq 18$ years old, (2) diagnosed as having type 2 diabetes, (3) urgency score of Overactive Bladder Symptom Score $\geq 2$ and a total score $\geq 3$, and (4) willing to participate in the study and capable of understanding study procedure and questions. The exclusion criteria were the following: (1) neurological disorders (such as stroke, Parkinson's disease, and multiple sclerosis), (2) active urinary tract infections, (3) history of bladder surgery, and (4) pelvic organ prolapse.

This study was approved by the Institutional Review Board of Shandong University. Written informed consent was obtained from each patient before the survey. The survey was completed anonymously, and the patients were assured that their responses would be kept confidential.

\section{Measures \\ Participant characteristics}

Health-related patient characteristics included body mass index (BMI), urinary tract infection history, comorbidity, duration of diabetes, and diabetes treatment (insulin and/ or anti-diabetic medication). The Charlson Comorbidity Index $(\mathrm{CCI})$ was used to measure a range of comorbid conditions for each patient. In this study, all patients had diabetes; thus, diabetes was not included in the calculation of CCI [26]. Each condition had a corresponding weight $(1,2,3$, or 6$)$, depending on mortality risk. A single comorbidity score was calculated for each patient by adding all the weights. The higher the score, the more likely mortality is predicted.

\section{$O A B$ symptom severity}

The Overactive Bladder Symptom Score (OABSS) was used to quantify $\mathrm{OAB}$ symptoms. The questionnaire was originally developed by Homma et al. [27], and was later validated by the Taiwanese Continence Society in the Chinese population [28]. The test-retest reliability of the Chinese OABSS was moderate to good [28] and the Cronbach's alpha coefficient was 0.65 in this study. The total OABSS is the sum of four symptom scores: daytime frequency (score 0-2), nighttime frequency (score 0-3), urgency (score 0-5), and urgency incontinence (score $0-5)$ [27]. The total score ranges from 0 to 15 , with a higher score indicating more severe $\mathrm{OAB}$ symptoms. In this study, all participants had an urgency score $\geq 2$ and a total score $\geq 3$. In the analyses, we dichotomized $O A B$ symptom severity into minor (total score $\leq 5$ ) and serious (total score $>5$ ) OAB.

\section{OAB bother}

The Patient Perception of Bladder Condition (PPBC) questionnaire, a single-item, 6 -point scale ( 1 = "no problems at all" to $6=$ "many severe problems"), was used to assess the $\mathrm{OAB}$ patients' impression of their bladder problems [29]. Construct validity, responsiveness, and test-retest reliability have been well-validated [29].

\section{Help-seeking behavior}

Help-seeking behavior was assessed by asking patients the following question: "Have you ever consulted health care professionals or received treatment for your urinary symptoms?"

\section{$O A B$-specific QOL}

The Overactive Bladder Questionnaire Short Form (OAB-q SF) was used to assess the effect of OAB symptoms on health-related quality of life [30]. The instrument has good internal consistency reliability, test-retest reliability, construct validity, and responsiveness [30]. The Cronbach's alpha coefficient was 0.72 in this study. The OAB-q SF consists of three QOL domains: coping, sleep, and emotional/social interaction. All scale scores were transformed to a 0 - to 100 -point scale, with lower scores indicating greater effect, i.e., worse QOL.

\section{Statistical analysis}

We used descriptive statistics to describe the sociodemographic and health-related characteristics of diabetic patients with OAB. To test our hypotheses on the relationships among OAB symptom severity, bother, help-seeking behavior, and QOL, as illustrated in Fig. 1, we conducted a two-step path analysis. Specifically, we used path analysis because it has the ability to test hypothesized relationships of a complex model. First, we explored the direct relationship between OAB symptom severity and QOL, without considering bother and helpseeking behavior in the model. If there was a significant relationship between $\mathrm{OAB}$ symptom severity and QOL, we then tested the full model by adding bother and help-seeking behavior in the path analysis. All models were adjusted for age, sex, education, marital status, living area, income, BMI, urinary tract infection history, $\mathrm{CCI}$, duration of diabetes, and diabetes treatment. Only two patients had a different race/ethnicity; thus, we did not control race/ethnicity in the path analysis. The goodness of model fit was evaluated using comparative fit index (CFI), Tucker-Lewis index (TLI), and root mean square error of approximation (RMSEA). A CFI and TLI $>0.90$ and a RMSEA $<0.06$ indicate a good fit to the data [31]. All statistical analyses were performed using Mplus (version 7.31; Muthén \& Muthén, Los Angeles, CA). Statistical significance was accepted at the $p<0.05$. 


\section{Results}

Table 1 shows the characteristics of 127 diabetic patients with $\mathrm{OAB}$. The mean age was approximately 63 years, and $46 \%$ of diabetic patients with $\mathrm{OAB}$ were women. The average duration of diabetes was 10.31 years, and $91.34 \%$ of patients received insulin therapy or antidiabetic medication. Thirty-five patients (27.56\%) had minor $\mathrm{OAB}$ and $92(72.44 \%)$ had serious OAB. With

Table 1 Characteristics of diabetic patients with $\mathrm{OAB}(N=127)$

\begin{tabular}{|c|c|}
\hline Variables & Mean \pm SD or $N(\%)$ \\
\hline Age (years) & $63.16 \pm 11.17$ \\
\hline \multicolumn{2}{|l|}{ Race/ethnicity } \\
\hline Han & $125(98.43 \%)$ \\
\hline Other & $2(1.57 \%)$ \\
\hline \multicolumn{2}{|l|}{ Sex } \\
\hline Female & $59(46.46 \%)$ \\
\hline Male & $68(53.54 \%)$ \\
\hline Years of education & $9.07 \pm 4.63$ \\
\hline \multicolumn{2}{|l|}{ Marital status } \\
\hline Married & 107 (84.25\%) \\
\hline Single/divorced/widowed & $20(15.75 \%)$ \\
\hline \multicolumn{2}{|l|}{ Living area } \\
\hline Urban & $100(78.74 \%)$ \\
\hline Rural & $27(21.26 \%)$ \\
\hline \multicolumn{2}{|l|}{ Income (RMB (USD)/month) } \\
\hline$\leq 3000(451)$ & $86(67.72 \%)$ \\
\hline$>3000(451)$ & $41(32.28 \%)$ \\
\hline Body mass index (BMI) & $25.59 \pm 3.87$ \\
\hline \multicolumn{2}{|l|}{ Urinary tract infection history ${ }^{a}$} \\
\hline Yes & $11(8.66 \%)$ \\
\hline No & $116(91.34 \%)$ \\
\hline Charlson Comorbidity Index $(\mathrm{CCl})^{\mathrm{b}}$ & $1.98 \pm 1.16$ \\
\hline Duration of diabetes (years) & $10.31 \pm 8.31$ \\
\hline \multicolumn{2}{|l|}{ Receiving diabetes treatment } \\
\hline Yes & $116(91.34 \%)$ \\
\hline No & $11(8.66 \%)$ \\
\hline \multicolumn{2}{|l|}{ OAB severity } \\
\hline Serious & $92(72.44 \%)$ \\
\hline Minor & $35(27.56 \%)$ \\
\hline OAB bother & $3.06 \pm 1.59$ \\
\hline \multicolumn{2}{|l|}{ Previous help-seeking behavior } \\
\hline Yes & $28(22.05 \%)$ \\
\hline No & 99 (77.95\%) \\
\hline Quality of life & $72.76 \pm 20.61$ \\
\hline
\end{tabular}

$S D$ standard deviation, $O A B$ overactive bladder, $R M B$ Chinese Yuan

${ }^{\text {a }}$ Patients who had a urinary tract infection at least 1 month before the survey

${ }^{b}$ Diabetes was not included in the calculation of Charlson Comorbidity

Index $(\mathrm{CCl})$ regard to bother, $14.17 \%$ reported that their bladder condition caused them severe problems, and $7.87 \%$ reported bladder condition caused them many severe problems. However, only $22.05 \%$ had a previous help-seeking behavior for their bladder condition. The score for OAB-specific QOL was about 72.76 (range 0-100).

The path analysis revealed the relationships among $\mathrm{OAB}$ symptom severity, bother, help-seeking behavior, and QOL (Table 2 and Fig. 1). A direct relationship between $\mathrm{OAB}$ symptom severity and QOL was found, indicating that the more severe the $\mathrm{OAB}$ symptom, the lower the QOL (model 1 in Table 2). However, when bother and help-seeking behavior was added in the model, the direct relationship between OAB symptom severity and QOL was attenuated and no longer significant (model 2 in Table 2). However the indirect relationship was significant: OAB symptom severity was positively associated with bother, which in turn had a negative association with QOL (Fig. 1). Moreover, bother had a positive association with help-seeking behavior, which in turn had an unexpected negative association with QOL. No direct relationship between OAB symptom severity and help-seeking behavior was observed. Thus, the more severe the $\mathrm{OAB}$ symptom, the more likely the patients felt bothered; patients bothered by their bladder problems tended to have a lower QOL and were more likely to seek help. Contrary to expectations, help-seeking behavior decreased QOL. The model indexes (RMSEA, CFI, and TLI) indicated that the full model (model 2) fitted the data well.

\section{Discussion}

To the best of our knowledge, this is the first quantitative study to investigate the relationships among $\mathrm{OAB}$ symptom severity, bother, help-seeking behavior, and QOL in patients with type 2 diabetes using a path analysis. Our findings supported most of our hypotheses. $\mathrm{OAB}$ symptom severity was directly associated with lower levels of QOL (hypothesis 1), and the strength of this association was no longer significant when taking bother and help-seeking behavior into account (hypothesis 4). Bother increased with OAB symptom severity, and patients with bothersome $\mathrm{OAB}$ tended to have lower levels of QOL (hypothesis 2). Hypothesis 3 was partially supported as only bother was related to help-seeking behavior. In contrast to our expectations, patients who sought help tended to have lower levels of QOL. Our findings provide important implications for the management of $\mathrm{OAB}$ in patients with diabetes to improve their QOL, with particular regards to help-seeking behavior.

The direct association between OAB symptom severity and lower levels of QOL is consistent with the findings of previous studies [9, 10, 32]. We further demonstrated that this direct association was attenuated and no longer 
Table 2 The relationships among OAB severity, bother, help-seeking behavior, and QOL

\begin{tabular}{|c|c|c|c|c|c|c|}
\hline & \multicolumn{3}{|c|}{$\begin{array}{l}\text { Model } 1 \text { without bother and previous help-seeking } \\
\text { behavior }\end{array}$} & \multicolumn{3}{|c|}{ Model 2 with bother and previous help-seeking behavior } \\
\hline & Coefficient & SE & $P$ value & Coefficient & SE & $P$ value \\
\hline OAB severity & -15.139 & 3.556 & $<0.001$ & -5.887 & 5.578 & 0.291 \\
\hline Bother & - & - & - & -5.685 & 1.050 & $<0.001$ \\
\hline Previous help-seeking behavior & - & - & - & -3.762 & 1.605 & 0.019 \\
\hline Age & -0.117 & 0.185 & 0.528 & -0.117 & 0.203 & 0.565 \\
\hline Sex (female vs. male) & 1.299 & 3.320 & 0.696 & 1.295 & 3.778 & 0.732 \\
\hline Years of education & -0.176 & 0.398 & 0.659 & -0.176 & 0.458 & 0.701 \\
\hline Marriage (married vs. unmarried) & 2.821 & 4.438 & 0.525 & 2.737 & 4.726 & 0.562 \\
\hline Living area (urban vs. rural) & 3.208 & 4.748 & 0.499 & 3.318 & 5.280 & 0.530 \\
\hline Income (>3000 vs. $\leq 3000)$ & 5.270 & 3.571 & 0.140 & 5.281 & 4.243 & 0.213 \\
\hline Body mass index (BMI) & -0.375 & 0.403 & 0.352 & -0.376 & 0.414 & 0.364 \\
\hline Urinary tract infection (UTI) ${ }^{\mathrm{a}}$ & -13.020 & 5.576 & 0.020 & -13.034 & 5.868 & 0.026 \\
\hline Charlson Comorbidity Index $(\mathrm{CCl})^{\mathrm{b}}$ & -3.621 & 1.539 & 0.019 & -3.621 & 1.722 & 0.035 \\
\hline Duration of diabetes & -0.511 & 0.240 & 0.033 & -0.511 & 0.237 & 0.031 \\
\hline Receiving diabetes treatment & 14.463 & 5.779 & 0.012 & 14.507 & 7.163 & 0.043 \\
\hline
\end{tabular}

$O A B$ overactive bladder, $Q O L$ quality of life, $S E$ standard error, $R M B$ Chinese Yuan

a Patients who had a urinary tract infection at least 1 month before the survey

${ }^{\mathrm{b}}$ Diabetes was not included in the calculation of Charlson Comorbidity Index (CCI)

significant after considering bother and help-seeking behavior. This result is somehow related to a previous finding indicating that gastrointestinal symptom severity is not only directly but also indirectly associated with QOL, which is mediated by bother (i.e., psychological distress) [33]. The major difference between previous studies and our study is the consideration of both bother and help-seeking behavior; other researchers have only looked into bother. The different study population may have also contributed to the dissimilar results.

Similar to earlier reports $[10,11,15,34]$, we found a positive association between perceived $O A B$ symptom severity and degree of bother and pointed at the central role of bother, which was a primary trigger for helpseeking behavior and related to lower QOL. The higher the degree of bother, the more likely an individual seeks for help [13, 14, 35]. A number of studies indicated that individuals with $\mathrm{OAB}$ were bothered by the need to use absorbent products, limited clothing choices, mapping out toilet locations, frequent voiding to prevent leakage episodes, concerns about urine odor, or self-imposed lifestyle constraints [36, 37]. These negative feelings would disrupt their daily lives and impair their wellbeing, supporting previous findings that $O A B$ has a detrimental effect on QOL.

The beneficial effect of help-seeking behavior on QOL was not supported by this study. Our results indicated that help-seeking behavior was negatively associated with QOL. Some studies identified misconceptions and miscommunication between patients and providers, and patients' dissatisfaction with the care they had received [38, 39].For example, patients had unrealistic expectations that their $\mathrm{OAB}$ problems could be cured with medication alone, and side effects, which were seldom understood by patients, often resulted in discontinuation $[38,39]$. In addition, some physicians failed to discuss the importance of behavioral modification with patients [38]. Botelho et al. stated that some health care providers have possibly assured that $\mathrm{OAB}$ symptoms are "normal," which could influence future help-seeking behavior [14]. Moreover, health care providers often attribute bladder symptoms to diabetes-related polyuria. Because of the misconceptions, miscommunication, and poor compliance with treatment, help-seeking behavior negatively affects QOL.

\section{Limitations}

Our study has some limitations. First, the small sample size and selection of diabetic patients from one hospital constrained the generalizability of the findings. Second, the causal inferences regarding the direction of the relationships illustrated in Fig. 1 are limited because of the cross-sectional nature of this study. According to the cognitive behavioral theory [40], a stimulus or trigger (OAB symptom severity) activates cognitive processes (bother), which in turn influence behavioral and emotional aspects (help-seeking behavior and QOL). It is also possible that poor 
QOL may worsen a patient's feeling of bother and lead to help-seeking behavior for OAB. Longitudinal studies to fully understand the direction of the relationships among symptom severity, bother, helpseeking behavior, and QOL are warranted. Third, satisfaction, knowledge, and experience after receiving treatment or consultation from health care providers were not measured; thus, we were not able to assess the underlying reasons for the association between help-seeking behavior and worse QOL.

\section{Conclusions}

This study addressed a gap in the literature by examining the role of bother and help-seeking behavior in the relationship between $\mathrm{OAB}$ symptom severity and QOL among patients with type 2 diabetes. To improve patients' QOL, health care providers should focus not only on symptom bother but also on dysfunctional help-seeking patterns. Nearly $80 \%$ of individuals with $\mathrm{OAB}$ had never sought help for their urinary symptoms, despite the problem being treatable or at least manageable. Moreover, this study's findings highlight the need for health education and promotion to improve patients' help-seeking behavior and health care provider's management of OAB symptoms during diabetic care. Furthermore, help-seekers' relatively poor QOL may be due to misconceptions and miscommunication with health care providers or poor compliance with treatment. Thus, promoting effective provider-patient communication, thereby increasing patients' understanding of bladder issues and adherence to treatments, is crucial to achieve satisfaction and improved QOL.

\section{Abbreviations}

CCl: Charlson Comorbidity Index; CFI: Comparative fit index; OAB: Overactive bladder; QOL: Quality of life; RMSEA: Root mean square error of approximation; TLI: Tucker-Lewis index

\section{Acknowledgements}

The authors thank all the patients for their participation.

\section{Funding}

This work was supported by a grant from the Natural Science Foundation of Shandong Province (No. ZR2015HM033).

\section{Availability of data and materials}

The dataset supporting the conclusions of this study will not be available in a public repository because consent/approval for the sharing of subject data was not obtained from the participants or Institutional Review Board of Shandong University.

\section{Authors' contributions}

KW designed the study. MZ and LH collected the data. DX analyzed the data. DX and MZ drafted the manuscript. KW supervised the study and made critical revisions to the manuscript for important intellectual content. All authors read and approved the final manuscript.

\section{Ethics approval and consent to participate}

This study was approved by the Institutional Review Board of Shandong University. All patients provided informed consent before the survey.
Consent for publication

Not applicable.

\section{Competing interests}

The authors declare that they have no competing interests.

\section{Publisher's Note}

Springer Nature remains neutral with regard to jurisdictional claims in published maps and institutional affiliations.

\section{Author details}

${ }^{1}$ School of Nursing, Shandong University, No. 44, Wenhua Xi Road, Jinan, Shandong 250012, People's Republic of China. ${ }^{2}$ School of Nursing, Purdue University, West Lafayette, Indiana 47907, USA.

Received: 23 March 2017 Accepted: 14 December 2017

Published online: 02 January 2018

\section{References}

1. Haylen BT, de Ridder D, Freeman RM, Swift SE, Berghmans B, Lee J, et al. An international Urogynecological association (IUGA)/international continence society (ICS) joint report on the terminology for female pelvic floor dysfunction. Neurourol Urodyn. 2010;29:4-20.

2. Irwin DE, Kopp ZS, Agatep B, Milsom I, Abrams P. Worldwide prevalence estimates of lower urinary tract symptoms, overactive bladder, urinary incontinence and bladder outlet obstruction. BJU Int. 2011;108:1132-8.

3. Chuang YC, Liu SP, Lee KS, Liao L, Wang J, Yoo TK, et al. Prevalence of overactive bladder in China, Taiwan and South Korea: results from a crosssectional, population-based study. Low Urin Tract Symptoms. 2017; https:// doi.org/10.1111/luts.12193.

4. Ganz ML, Smalarz AM, Krupski TL, Anger JT, JC H, Wittrup-Jensen KU, et al. Economic costs of overactive bladder in the United States. Urology. 2010;75:526-32.

5. Irwin DE, Mungapen L, Milsom I, Kopp Z, Reeves P, Kelleher C. The economic impact of overactive bladder syndrome in six western countries. BJU Int. 2009:103:202-9.

6. Inoue S, Kobayashi M, Sugaya K. Economic impact of overactive bladder symptoms in Japan. Nihon Hinyokika Gakkai Zasshi. 2008;99:713-22.

7. Bartoli S, Aguzzi G, Tarricone R. Impact on quality of life of urinary incontinence and overactive bladder: a systematic literature review. Urology. 2010;75:491-500.

8. Sexton CC, Coyne KS, Thompson C, Bavendam T, Chen Cl, Markland A. Prevalence and effect on health-related quality of life of overactive bladder in older americans: results from the epidemiology of lower urinary tract symptoms study. J Am Geriatr Soc. 2011:59:1465-70.

9. Vaughan CP, Johnson TM, Ala-Lipasti MA, Cartwright R, Tammela TL, Taari K, et al. The prevalence of clinically meaningful overactive bladder: bother and quality of life results from the population-based FINNO study. Eur Urol. 2011;59:629-36.

10. Gotoh M, Kobayashi T, Sogabe K. Characterization of symptom bother and health-related quality of life in Japanese female patients with overactive bladder. Neurourol Urodyn. 2015;34:730-5.

11. Homma Y, Gotoh M. Symptom severity and patient perceptions in overactive bladder: how are they related? BJU Int. 2009:104:968-72.

12. Irwin DE, Milsom I, Kopp Z, Abrams P, EPIC Study Group. Symptom bother and health care-seeking behavior among individuals with overactive bladder. Eur Urol. 2008;53:1029-39.

13. de Ridder $D$, Roumeguere $T$, Kaufman $L$. Overactive bladder symptoms, stress urinary incontinence and associated bother in women aged 40 and above; a Belgian epidemiological survey. Int J Clin Pract. 2013;67:198-204.

14. Botelho EM, Elstad EA, Taubenberger SP, Tennstedt SL. Moderating perceptions of bother reports by individuals experiencing lower urinary tract symptoms. Qual Health. 2011;21:1229-38.

15. Xu D, Wang X, Li J, Wang K. The mediating effect of 'bothersome' urinary incontinence on help-seeking intentions among community-dwelling women. J Adv Nurs. 2015;71:315-25.

16. Coyne KS, Sexton CC, Kopp Z, Chapple CR, Kaplan SA, Aiyer LP, et al. Assessing patients' descriptions of lower urinary tract symptoms (LUTS) and perspectives on treatment outcomes: results of qualitative research. Int J Clin Pract. 2010;64:1260-78. 
17. Wennberg AL, Molander U, Fall M, Edlund C, Peeker R, Milsom I. Lower urinary tract symptoms: lack of change in prevalence and help-seeking behaviour in two population-based surveys of women in 1991 and 2007. BJU Int. 2009:104:954-9.

18. Altman D, lliadou AN, Lundholm C, Milsom I, Pedersen NL. Somatic comorbidity in women with overactive bladder syndrome. J Urol. 2016;196:473-7.

19. Berges RR, Pientka L, Hofner $K$, Senge T, Jonas U. Male lower urinary tract symptoms and related health care seeking in Germany. Eur Urol. 2001;39:682-7.

20. Burgio KL, Goode PS, Johnson TM II, Hammontree L, Ouslander JG. Markland ADet al. Behavioral versus drug treatment for overactive bladder in men: the male overactive bladder treatment in veterans (MOTIVE) trial. J Am Geriatr Soc. 2011;59:2209-16.

21. Lofgren OE. Overactive bladder: a better understanding of pathophysiology diagnosis and management. J Urol 2007;178:1553-53.

22. Burgio KL, Goode PS, Richter HE, Markland AD, Johnson TM, Redden DT. Combined behavioral and individualized drug therapy versus individualized drug therapy alone for urge urinary incontinence in women. J Urol. 2010; 184:598-603.

23. Karoli R, Bhat S, Fatima J, Priya SA. Study of bladder dysfunction in women with type 2 diabetes mellitus. J Endocrinol Metab. 2014;18:552-7.

24. Palleschi G, Pastore AL, Maggioni C, Fuschi A, Pacini L, Petrozza V, et al. Overactive bladder in diabetes mellitus patients: a questionnaire-based observational investigation. World J Urol. 2014;32:1021-5.

25. Xu D, Gao J, Wang X, Huang L, Wang K. Prevalence of overactive bladder and its impact on quality of life in 1025 patients with type 2 diabetes in mainland China. J Diabetes Complicat 2017. 31:1254-8.

26. Charlson ME, Pompei $\mathrm{P}$, Ales KL, Mackenzie CRA. New method of classifying prognostic comorbidity in longitudinal studies: development and validation. J Chronic Dis. 1987;40:373-83.

27. Homma Y, Yoshida M, Seki N, Yokoyama O, Kakizaki H, Gotoh M, et al. Symptom assessment tool for overactive bladder syndrome - overactive bladder symptom score. Urology. 2006:68:318-23.

28. Hung MJ, Chou CL, Yen TW, Chuang YC, Meng E, Huang ST, et al. Development and validation of the Chinese overactive bladder symptom score for assessing overactive bladder syndrome in a RESORT study. J Formos Med Assoc. 2013;112:276-82.

29. Coyne KS, Matza LS, Kopp Z, Abrams P. The validation of the patient perception of bladder condition (PPBC): a single-item global measure for patients with overactive bladder. Eur Urol. 2006;49:1079-86.

30. Coyne KS, Thompson CL, Lai JS, Sexton CC. An overactive bladder symptom and health-related quality of life short-form: validation of the OAB-q SF. Neurourol Urodyn. 2015;34:255-63.

31. LT H, Bentler PM. Cutoff criteria for fit indexes in covariance structure analysis: conventional criteria versus new alternatives. Struct Equ Modeling. 1999;6:1-55.

32. Takao T, Tsujimura A, Kiuchi H, Takezawa K, Okuda H, Yamamoto K, et al. Correlation between overactive bladder symptoms and quality of life in Japanese male patients: focus on nocturia. Urology. 2013;82:189-93.

33. Naliboff BD, Kim SE, Bolus R, Bernstein CN, Mayer EA, Chang L. Gastrointestinal and psychological mediators of health-related quality of life in IBS and IBD: a structural equation modeling analysis. Am J Gastroenterol. 2012:107:451-9.

34. Zhang L, Zhu L, Xu T, Lang J, Li Z, Gong J, et al. A population-based survey of the prevalence, potential risk factors, and symptom-specific bother of lower urinary tract symptoms in adult Chinese women. Eur Urol. 2015;68:97-112.

35. Gao J, Cheng R, Chen L, Wang X, Wang K. Help-seeking behavior among individuals with overactive bladder in type 2 diabetes mellitus and its influencing factors. Chin J Prac Nurs. 2016;32:571-5.

36. Anger JT, Nissim HA, Le TX, Smith AL, Lee U, Sarkisian C, et al. Women's experience with severe overactive bladder symptoms and treatment: insight revealed from patient focus groups. Neurourol Urodyn. 2011;30:1295-9.

37. Coyne KS, Matza LS, Brewster-Jordan J. "We have to stop again?!": the impact of overactive bladder on family members. Neurourol Urodyn. 2009; 28:969-75.

38. Smith AL, Nissim HA, Le TX, Khan A, Maliski SL, Litwin MS, et al. Misconceptions and miscommunication among aging women with overactive bladder symptoms. Urology. 2011;77:55-9.

39. Siu YM. Communicating with mismatch and tension: treatment provision experiences of primary care doctors treating patients with overactive bladder in Hong Kong. BMC Fam Pract. 2015;16:160-70.

40. Ellis TE. Learning cognitive-behavior therapy: an illustrated guide. B Menninger Clin. 2009;73:149-50.

\section{Submit your next manuscript to BioMed Central and we will help you at every step:}

- We accept pre-submission inquiries

- Our selector tool helps you to find the most relevant journal

- We provide round the clock customer support

- Convenient online submission

- Thorough peer review

- Inclusion in PubMed and all major indexing services

- Maximum visibility for your research

Submit your manuscript at www.biomedcentral.com/submit
Biomed Central 